protein synthesis is likely to be regulated at the translational level by the availability of eertain species of $t$ RNA.

In the same journal (ibid., 454), Leder, Skogerson and Nau report the purification of an enzyme which can also control the rate of protein synthesis. They have purified the $E$. col $i \mathrm{G}$ factor of Nishizuka and Lipmann, which is equivalent to the factor $S_{2}$ in Bacillus stearothermophilus (see this issue of Nature, pages 626 and 645). Factor $\mathrm{G}$, or $\mathrm{S}_{2}$, is a translocase which catalyses the translocation of $m \mathrm{RNA}$ and peptidyl $t \mathrm{RNA}$ from the amino to the peptidyl site in ribosomes. The enzyme is a fairly large monomeric protein, with a molecular weight of about 72,000 daltons, which comprises more than 2 per cent of the total protein in a ribosome free extract of $E$. coli; this high concentration no doubt reflects the importance of the enzyme in protein synthesis. In vitro, at least, the rate of protein synthesis is linearly proportional to the concentration of translocase until the reaction mixture contains one molecule of enzyme per ribosome.

The cyclical dissociation of $70 \mathrm{~S}$ ribosomes into $30 \mathrm{~S}$ and $50 S$ subunits is another stage in protein synthesis available for regulatory mechanisms. Evidence is slowly accumulating that the $70 \mathrm{~S}$ ribosomes released from a polysome when they have completed the synthesis of protein molecules do not spontaneously dissoci. ate into the two subunits, but instead form a pool of free $70 \mathrm{~S}$ ribosomes. The current idea is that these $70 \mathrm{~S}$ ribosomes have to react with a dissociation factor in order to split into subunits. Previous reports that dissociation is spontaneous, founded on the failure to detect $70 \mathrm{~S}$ ribosomes in the lysates of bacteria, are being discounted because the conditions of lysis probably caused artefactual dissociation of the $70 \mathrm{~S}$ monomers. Confirming the observations of Kohler et al. (J. Mol. Biol., 36, 71; 1968), Algranati et al. (Proc. US Nat. Acad. Sci., 62, 574; 1969) claim that in both $E$. roli and $B$. stearothermophilus $70 \mathrm{~S}$ ribosomes are the final product of translation and, if initiation of new protein chains is blocked, $70 \mathrm{~S}$ ribosomes, not $30 \mathrm{~S}$ and $50 S$ subunits, accumulate.

\section{BIOCHEMICAL ILLNESS}

\section{Analysing Huntington's Chorea}

\section{from our Medical Biochemistry Correspondent}

Patients with Huntington's chorea suffer from progressive mental degeneration as well as spasmodic incoordinated movements, and although the disease does not usually become apparent until late in adult life there is no doubt that it is genetically determined. The involuntary movements of sufferers are similar to those in degenerative conditions like Parkinson's discase and the mental changes are similar to the emotional illnesses known as psychoses, so that the scarch for a biochemical defect in this condition is of great interest. The search has so far proved fruitless, but Perry et al. (Lancet, i, 806; 1969) have shown recently that there are significant differences in the concentrations of six amino-acids in the plasma of patients with Huntington's chorea.

They used an amino-acid analyser to measure the concentrations of individual amino-acids in the plasma of nineteen patients with Huntington's chorea, twenty healthy adults and eighteen schizophrenies who were living in the same hospital conditions as some of the choreic patients (nine of the patients with Huntington's chorea were still living at home). The concentrations of twelve amino-acids were found to be significantly lower in the patients than in the normal group. Compared with the schizophrenic group, however, there were significant differences in the concentration $(P<0.02)$ of only six amino-acids - proline, alanine, tyrosine and the three branched chain amino-acids valine, leucine and isoleucine. Analysis of the cerebrospinal fluid from ten choreic patients and ten healthy controls showcd that there was less alanine, leucine, valine and tyrosine samples from patients with Huntington's chorea, but the difference was not so significant $(P<0 \cdot 05)$ as in plasma.

The decreases are probably not a consequence of drug treatment. Six of the patients with Huntington's chorea were taking no drugs at all and the others were all taking the same phenothiazine tranquillizers as the schizophrenic patients. Paper chromatograms of the urine indicated that the quantities of aminoacids in the urine of patients with Huntington's chorea were normal so that the low concentrations of aminoacids in plasma are not caused by excessive excretion. Unfortunately the individual variation in concentrations was so great that it is not possible to use the difference in concentration of amino-acids as a diagnostic test for the condition. The ratio of alanine to glycine was less than one in ten out of nineteen with Huntington's chorea and more than one in sixteen out of eighteen schizophrenics and one in nineteen out of twenty normal people. A low ratio is therefore a very good indication of Huntington's chorea but is not an exclusive sign of this condition. Although the magnitude of the deviation from normal is small, this is the first sign of an underlying biochemical defeet in a condition similar to the psychoses and Parkinson's disease, and is a starting point for further research into these conditions.

\section{PROTEINS \\ GTP and Synthesis}

\section{from our Biochemical Genetics Correspondent}

Keller and Zamecnik discovered in 1956 that GTP was required for protein synthesis studicd in vitro. The next important discovery was made by Monro and by Conway and Lipmann in 1964, when it was shown that, of the different protein factors required during protein synthesis ( $T_{u}, T_{s}$ and $G$ ), one of them, $G$, could hydrolyse GTP to GDP and inorganic phosphate in the presence of ribosomes. This clearly implicated the G factor as that factor which utilized GTP. Because the only obvious step in which energy might be required in protein synthesis is during translocation that is, the physical movement of both the messenger RNA and the peptidyl-tRNA on the ribosome from one site to another-it has been supposed that $C$, and therefore GTP, are required for translocation. During the past two years, GTP has become implicated in two other steps in bacterial protein synthesis. The initiating $t \mathrm{RNA}$, formylmethionyl-tRNA, is bound to ribosomes by its codon, AUG, in the presence of "initiation factors" and G'TP. When the $\beta-\gamma$ methylene analogue of GTP, GMP.PCP, is substituted for GTP, formylmethionyl-tRNA is bound to ribosomes in the presence 